\title{
ANALISIS OPTIMALISASI SARANA DAN PRASARANA BIDANG KEUANGAN SATKER ITWASDA POLDA LAMPUNG TERHADAP PENINGKATAN PELAYANAN SATKER
}

\author{
Nuzleha $^{(1)^{*}}$, Iwan Zulfikar ${ }^{(2)}$, Eka Suryanti ${ }^{(3)}$ \\ Fakultas Ekonomi Universitas Sang Bumi Ruwa Jurai \\ nuzlehahadjar1970@gmail.com,iwanzulfikar4@gmail.com,ekasuryanti12@gmail.com
}

\begin{abstract}
Abstrak. Tujuan penelitian ini agar dapat dideskripsikan optimalisasi sarana dan prasarana, dapat diketahui pula kemampuan yang dimiliki personel SATKER ITWASDA POLDA Lampung guna meningkatkan kualitas pelayanan SATKER. Metode penelitian yang digunakan dalam penelitian ini deskriptif dengan pendekatan kualitatif. Pengumpulan data penelitian menggunakan teknik dan sejumlah data yang diambil berasal dari sampel pada anggota personel bidang keuangan SATKER ITWASDA POLDA Lampung yang berlangsung pada Tahun 2017/ 2018 dan Tahun 2018/2019. Teknik pengumpulan data adalah observasi, wawancara, dan dokumentasi. Sampel dari penelitian ini berjumlah 37 Personel ITWASDA POLDA. Berdasarkan hasil analisis, maka dapat disimpulkan bahwa sarana dan prasarana bidang keuangan untuk meningkatkan kualitas pelayanan SATKER, sehingga berimplikasi pada kuantitas karena institusi Polri harus mampu melaksanakan tugas pokok dan fungsinya dengan baik sesuai ekspektasi masyarakat yang selalu berubah mengikuti perkembangan lingkungan sosial kemasyarakatan yang bergerak sangat cepat. Hal inilah yang menjadi hambatan personel SATKER ITWASDA POLDA Lampung dalam membentuk insan Polri yang Profesional, Modern, dan Terpercaya, menjadi kebanggaan masyarakat, karena dapat memaksimalkan personelnya guna keprofesionalan (profesionalisme) setiap petugas / anggota penyelenggara pelayanan publik (dalam hal ini Polri)
\end{abstract}

Kata Kunci: optimalisasi, sarana dan prasarana, kualitas pelayanan.

\section{PENDAHULUAN}

Organisasi adalah suatu kelompok yang mempunyai serangkaian kegiatan yang diperlukan untuk mencapai suatu tujuan. Agar tujuan organisasi dapat tercapai secara efektif dan efisien, maka organisasi tersebut harus memanfaatkan sumber daya yang ada baik sumber daya manusianya yang telah ditempatkan untuk melakukan aktivitas tertentu sesuai dengan keahliannya masingmasing maupun sumber daya lainnya seperti alat-alat yang diperlukan. Sedangkan, Satuan Kerja merupakan Kuasa Pengguna Anggaran / Kuasa Pengguna Barang yang merupakan bagian dari suatu unit organisasi pada Kementerian Negara / Lembaga yang melaksanakan satu atau beberapa kegiatan dari suatu program (PERATURAN
MENTERI KEUANGAN NOMOR 196/ PMK.05/ 2008).

Menurut Haksever pelayanan yang dikemukakan omenyatakan bahwa jasa atau pelayanan (services) didefinisikan sebagai kegiatan ekonomi yang menghasilkan waktu, tempat, bentuk dan kegunaan psikologis.(Fikri et al., 2016) Pelayanan yang berkualitas berperan penting dalam membentuk kepuasan konsumen, selain itu juga erat kaitannya dalam menciptakan keuntungan bagi perusahaan. Semakin berkualitas pelayanan yang diberikan oleh perusahaan maka kepuasan yang dirasakan oleh pelanggan akan semakin tinggi.(Yuliati, 2016)

Pelayanan dapat didukung dengan adanya sarana dan prasana. Menurut 
Muhammad dalam Yunari Sarana prasarana pelayanan kesehatan dapat didefinisikan sebagai proses kerjasama pendayagunaan semua sarana dan prasarana kesehatan secara efektif dan efisien untuk memberikan layanan secara profesional dibidang sarana dan prasarana dalam proses pelayanan kesehatan yang efektif dan efisien pula.(Ristiani, 2017)

Polri sebagai salah satu institusi, membutuhkan 'corong' yang paling efektif bagi sosialisasi kerja, baik Polri dan penjelasan yang berimbang ini berkaitan dengan keterlibatan institusi maupun personel anggota Polri yang mempunyai derajat sensitivitas yang tinggi pula. Maka, dibutuhkan tidak hanya pemimpin dan personel yang cakap semata, namun juga yang memiliki integratif institusional yang berirama sama ketika memposisikan Polri sebagai institusi Keamanan dalam Negeri (Kamdagri) untuk mampu menjawab harapan serta keinginan publik tanpa harus bertentangan terhadap peran dan fungsi polri, sebagimana yang telah diatur dalam UU No. 2 / 2017 Tentang Polri.

Seiring dengan itu pula melalui Peraturan Kepala Kepolisian Negara Republik Indonesia Nomor 22 Tahun 2010 Tentang Ketentuan Umum Polri yang berperan dalam memelihara keamanan dan ketertiban masyarakat, menegakkan hukum, serta memberikan perlindungan, pengayoman, dan pelayanan kepada masyarakat dalam rangka terpeliharanya keamanan dalam negeri. Salah satunya peran dari ITWASDA (Inspektorat Pengawasan Daerah) adalah unsur pengawas dan pembantu pimpinan pada tingkat POLDA yang berada di bawah Kapolda.

Peraturan tersebut memiliki tujuan untuk dijadikan sebagai pedoman dalam pelaksanaan tugas guna menyamakan pola pikir dan pola tindak dalam penyelenggaraan tugas pokok dan fungsi satuan organisasi
POLDA, salah satunya yang berada di Provinsi Lampung yakni SATKER ITWASDA POLDA Lampung. Prinsipprinsip yang selalu dipegang kukuh oleh SATKER ITWASDA POLDA Lampung, adalah antara lain.

1. Profesional, yaitu dalam melaksanakan tugas pokok dan fungsi satuan organisasi dilaksanakan sesuai dengan kemampuan dan kompetensi yang dimiliki setiap personel SATKER.

2. Prosedural, yaitu dilaksanakan dengan mekanisme dan tata cara sesuai dengan ketentuan peraturan perundangundangan yang berlaku. Akuntabel, yaitu dapat dipertanggungjawabkan

3. Transparan, yaitu dilaksanakan secara terbuka sesuai dengan ketentuan peraturan perundang-undangan.

4. Nesesitas, yaitu dalam penentuan jabatan struktural disesuaikan dengan kebutuhan organisasi/ SATKER.

Upaya menggeser citra Polri yang dulunya militeristrik ke arah polisi sipil yang demokratik, profesional, akuntabel, dan indipenden masih menjadi tantangan bagi Polri di masa mendatang (Yanuarti, Sri: 2011). Untuk menunjang kelancaran pelaksanaan kegiatan suatu instansi / organisasi diperlukan sarana dan prasarana yang harus dikelola dengan baik sehingga dapat berfungsi sebagaimana mestinya. Pengelolaan sarana dan prasarana tersebut dilakukan melalui suatu proses atau rangkaian kegiatan dalam rangka mengatur, menata, dan mengorganisir secara sistematis dan berdayaguna semua sarana dan prasarana yang ada menurut fungsinya masing-masing dalam rangka menunjang pencapaian tujuan secara efisien dan efektif yang disebut juga dengan manajemen sarana dan prasarana.

Pengelolaan optimalisasi sarana dan prasarana di lingkungan Kepolisian disebut juga dengan akuntansi Barang Milik Negara 
yang diatur dalam Surat Keputusan Kepala Kepolisian Negara Republik Indonesia No. Pol: SKEP/ 330/ V/ 2005 akuntansi Barang Milik Negara $(\mathrm{BMN})$ adalah suatu urutan kegiatan dalam pengelolaan Barang Milik Negara (BMN) yang mengolah seluruh transaksi Barang Milik Negara (BMN) untuk menghasilkan informasi yang diperlukan sebagai pertanggungjawaban atas pengelolaan Barang Milik Negara (BMN)

Salah satu upaya memberdayakan pegawai dan pengembangannya, pihak manajerial berupaya melakukan tugas fungsinya melalui planning, organizing, staffing, directing, dan controlling dengan tujuan agar bisa mencapai sasaran.(Rodin, 2019)

Berdasarkan penelitian sebelumnya tentang Analisis Kualitas Pelayanan, Sarana Prasarana Dan Lingkungan Terhadap Kepuasan Pasien didapatkan hasil bahwa adanya pengaruh yang signifikan antara kualitas pelayanan, sarana prasarana dan lingkungan terhadap kepuasan pasien di Puskesmas ( $\mathrm{p}$ value $0,034<0,05)$. Pengaruhnya bersifat positif dan termasuk kuat (correlation +0.910$)$, artinya semakin tinggi skor kualitas pelayanan, sarana prasarana dan lingkungan maka semakin tinggi skor kepuasan pasien dan sebaliknya.

Ketiga elemen tersebut berpengaruh terhadap kepuasan pelanggan, sehingga disarankan agar petugas memfokuskan kepada ketiga hal tersebut sebagai strateginya untuk memuaskan pelanggan dan diharapkan tim audit internal secara berkala melakukan penilaian terhadap ketiga hal dan dievaluasi secara berkala.(Ulandari \& Yudawati, 2019)

Berdasarkan penelitian bahwa pengelolaan sarana dan prasarana yang ada di sekolah kepala sekolah dapat merencanakan dan mendata apa saja sarana dan prasarana yang harus digunakan di sekolah tersebut. Jika semua langkahlangkah pengelolaan telah berjalan dengan baik seperti yang diharapkan maka akan berdampak positif terhadap siswa-siswa dalam proses belajar mengajar dan tercapainya tujuan pendidikan secara efektif dan efisien. Maka penyelenggara pendidikan baik itu pemerintah, kepala sekolah, guru, personil sekolah yang lainnya maupun masyarakat perlu terus berusaha untuk meningkatkan kualitas pendidikan sesuai dengan tuntutan zaman.(Megasari, 2014).

Hal ini sejalan dengan kutipan Hasibuan (Hasibuan, 2005) menyatakan bahwa mengelola dengan menyediakan optimalisasi sarana dan prasarana bidang keuangan SATKER ITWASDA POLDA Lampung dalam rangka mewujudkan lingkungan kerja dan iklim kerja yang kondusif diharapkan dapat mendorong pegawai selalu berinovasi dan berkreasi termasuk membuat sistem yang fair dan struktur yang fleksibel dengan pembagian tugas, wewenang, dan tanggung jawab yang jelas dan manusiawi dengan memerhatikan kemampuan pegawai dan usahanya dalam mencapai tujuan karirnya.

Ketika cara menganalisis optimalisasi sarana dan prasarana, kemampuan, dalam sebuah profesi mutlak diperlukan guna meningkatkan pelayanan publik di salah satu instansi maupun institusi. Oleh sebab itu, peneliti akan mengangkat dalam bentuk karya tulis ilmiah dengan judul "Analisis Optimalisasi Sarana dan Prasarana Bidang Keuangan SATKER ITWASDA POLDA Lampung Terhadap Peningkataan Kualitas Pelayanan SATKER".

\section{METODE PENELITIAN}

Metode penelitian dengan judul "Analisis Optimalisasi Sarana dan Prasarana Bidang Keuangan SATKER ITWASDA POLDA Lampung Terhadap Peningkatan Kualitas Pelayanan SATKER" 
ini menggunakan pendekatan kualitatif. Menurut Sugiyono (2012: 9) mengemukakan bahwa metode penelitian yang menggunakan pendekatan kualitatif ini merupakan metode penelitian yang digunakan untuk meneliti pada kondisi obyek yang alamiah, maksudnya data yang dikumpulkan bukan berupa angka-angka, melainkan data yang berasal dari wawancara, catatan lapangan, catatan memo, dokumen pribadi, dan dokumen resmi. Teknik pengumpulan data pada penelitian ini, ialah observasi, wawancara dan dokumentasi.

\section{HASIL DAN PEMBAHASAN}

Berdasarkan penelitian tentang analisis optimalisasi sarana dan prasarana bidang keuangan satker itwasda polda lampung terhadap peningkatan pelayanan satker diperoleh hasil sebagai berikut :

a. Analisis Optimalisasi Sarana dan Prasarana Bidang Keuangan yang Digunakan Personel SATKER ITWASDA POLDA Lampung dalam Meningkatkan Kualitas Pelayanan SATKER

Optimaliasasi sarana dan prasarana sebagai bagian dari penunjang pelayanan personal SATKER ITWASDA POLDA Lampung terhadap SATKER dalam hal pelaporan keuangan ataupun dalam hal manajemen keuangan masih dinilai kurang dalam hal pelayanannya. Hal ini tentu harus disikapi dengan baik oleh para wasrik guna memantau cara kerja personel SATKER ITWASDA POLDA Lampung dalam meningkatkan sarana dan prasarana di bidang keuangan.

Pengetahuan yang dimiliki oleh personel SATKER ITWASDA POLDA Lampung dalam rangka meningkatkan sarana dan prasarana di bidang keuangan guna meningkatkan pelayanan, saat ini belum ditunjang dengan sistem / metode yang efektif dan efisien. Hal ini berkoreasi dengan sumber daya manusia yang ada, yang didominasi oleh personel yang hanya lulusan SMA.

Umumnya, lulusan S1 memiliki pandangan dan cakrawala yang cukup luas jika dibandingkan dengan personel yang lulusan SMA. Tidak sedikit personel yang hanya lulusan SMA dapat memahami tata kerja di bidangnya. Namun, fakta di lapangan terkait analisis optimalisasi yang digunakan oleh personel SATKER ITWASDA POLDA Lampung guna meningkatkan sarana dan prasarana Bidang Keuangan dalam meningkatkan kualitas pelayanan SATKER belum optimal.

\section{b. Faktor-Faktor yang Mempengaruhi Optimalisasi Sarana dan Prasarana Bidang Keuangan SATKER ITWASDA POLDA Lampung Terhaap Peningkatan Kualitas Pelayanan SATKER}

\section{Faktor Internal}

\section{a) Kelebihan}

1) Tersedianya piranti lunak berupa peraturan peraturan perundangundangan seperti Undang-Undang Republik Indonesia Nomor 2Tahun 2002 Tentang Kepolisian Negara Republik Indonesia, Peraturan Kepala Kepolisian Negara Republik Indonesia Nomor: 22 Tahun 2010 tanggal 28 September 2010 Tentang Struktur Organisasi dan Tata Kerja tingkat POLDA;

2) Kepolisian Negara Republik Indonesia telah mengambil langkah reformasi menuju Lembaga Kepolisian yang Profesional, Modern, dan Terpercaya dengan pembenahan berkelanjutan pada 
reformasi struktrual, instrumental dan kultural;

3) Reformasi instrumental berupa perubahan sistem dan metode yang antara lain meliputi piranti lunak fungsi fasilitas, penganggaran, sistem dan metode, pelatihan dan fungsi operasi Kepolisian antara lain perencanaan berbasis kenyataan dan anggaran berbasis kinerja, manajemen operasional Kepolisian, pembenahan manajemen sumber daya manusia (sistem rekrutmen, sampai seleksi dan pendidikan, sistem penilaian kinerja, sistem jalur karir, sampai pada sistem personel berseragam dan tidak berseragam), sehingga diharapkan postur Polri dapat terwujud;

4) Reformasi struktural antara lain mewujudkan paradigma baru pada organisasi Polri berupa postur Polri yang Profesional, Modern dan Terpercaya dalam kerangka revolusi mental;

5) Reformasi kultural telah meletakkan landasan dalam bentuk pembenahan manajemen sumber daya manusia dengan berorientasi strategi guna meletakkan dasardasar budaya perilaku Polri yang mahir, terpuji dan patuh hukum serta berwibawa dan berkinerja secara profesional.

\section{a) Kekurangan}

1) Kuantitas personel SATKER ITWASDA POLDA Lampung dalam meningkatkan kualitas pelayanan Satker yang belum terpenuhi;

2) Kualitas personel SATKER ITWASDA POLDA Lampung didominasi oleh personel yang belum ditunjang dengan ilmu dan pengetahuan yang cukup di bidang Penyusunan Laporan Realisasi Anggaran (LRA) dan pembuatan laporan akuntabilitas kinerja Satuan Kerja (SATKER);

\section{Faktor Eksternal}

\section{a) Peluang}

1) Adanya dukungan dari pimpinan guna mewujudkan pelayanan fungsi keuangan yang meliputi pembiayaan, pengendalian, pembukuan, akuntansi dan penyusunan Laporan Sistem Akuntansi Instansi (SAI), serta pertanggungjawaban keuangan, dan Penyusunan Laporan Realisasi Anggaran dan pembuatan laporan akuntabilitas kinerja Satuan Kerja;

2) Adanya tuntutan masyarakat terhadap kinerja Polri yang Profesional, Modern, dan Terpercaya Adanya dukungan dari pemerintah dan swasta terhadap kemajuan profesionalisme;

\section{b) Kendala}

1) Kurangnya kualitas dan kuantitas personel SATKER ITWASDA POLDA Lampung guna meningkatkan sarana dan prasarana Bidang Keuangan dalam meningkatkan kualitas pelayanan Satker;

2) Kurangnya pengetahuan dan kemampuan yang dimiliki oleh personel SATKER ITWASDA POLDA Lampung dalam Penyusunan Laporan Realisasi Anggaran dan pembuatan laporan akuntabilitas kinerja Satuan Kerja yang menjadikan pelaksanaan 
pengawasan dan pemeriksaan yang dilaksanakan belum sesuai dengan harapan Pimpinan;

c. Kondisi Personel yang Diharapkan dalam Optimalisasi Sarana dan Prasarana Bidang Keuangan SATKER ITWASDA POLDA Lampung Terhadap Peningkatan Kualitas Pelayanan SATKER

Kondisi personel yang diharapkan dalam rangka optimalisasi sarana dan prasarana Bidang Keuangan SATKER ITWASDA POLDA Lampung terhadap peningkatan kualitas pelayanan SATKER secara profesional, Modern, dan Terpercaya dalam kerangka revolusi mental, ialah antara lain.

1. Memiliki kualitas yang meningkat di tubuh SATKER ITWASDA POLDA Lampung;

2. Memiliki pengetahuan dan kemampuan yang meningkat dalam peningkatan kualitas pelayanan SATKER secara profesional, Modern, dan Terpercaya;

\section{d. Upaya-Upaya dalam Optimalisasi Sarana dan Prasarana Bidang Keuangan SATKER ITWASDA POLDA Lampung Guna Meningkatkan Kualitas Pelayanan SATKER}

Guna meningkatkan profesionalitas, ada beberapa upaya yang dilakukan oleh SATKER ITWASDA POLDA Lampung dalam meningkatkan kualitas personel SATKER ITWASDA POLDA Lampung, adalah sebagai berikut.

1. Upaya meningkatkan kemampuan personel SATKER ITWASDA POLDA Lampung:

a) Mengusulkan kepada pimpinan terkait mengikuti Dikjur Pengawasan/ Diklat
Auditing baik dasar maupun menengah dan audit investigasi;

b) Menginstruksikan kepada semua personel agar masuk ke Perguruan Tinggi (S1) agar dapat menunjang dalam kerja dan kinerjanya.

2. Upaya meningkatkan keterampilan personel SATKER ITWASDA POLDA Lampung:

a) Mengikuti pelatihan-pelatihan, dan mengikuti dikjur yang berkaitan dengan bidangnya dalam meningkatkan kualitas personel SATKER ITWASDA POLDA Lampung;

b) Mengikuti seminar dan dikbangpes guna meningkatkan kualitas personel SATKER ITWASDA POLDA Lampung.

3. Upaya meningkatkan Kualitas Pelayanan SATKER yang digunakan personel SATKER ITWASDA POLDA Lampung:

a) Mendatangkan instruktur dari pihak luar guna menambah kualitas dan kuantitas anggota Polri pada umumnya khususnya personal SATKER ITWASDA POLDA Lampung;

b) Adanya kerjasama dengan personal lainnya dan pemerintah dalam meningkatkan kualitas personel SATKER ITWASDA POLDA Lampung.

\section{Secara Parsial (Bagian dari Keseluruhan) \\ Hasil uji hipotesis yang dilakukan secara parsial, adalah sebagai berikut.}




\section{Kemampuan Personel SATKER ITWASDA POLDA Lampung Terhadap Peningkatan Kualitas Pelayanan SATKER}

Kelengkapan sarana dan prasarana kerja, peralatan kerja, dan pendukung lainnya yang memadai termasuk penyediaan sarana dan teknologi telekomunikasi dan informatika pada satuan kerja untuk kemudahan akses. Hal inilah yang menjadi faktor penghambat dari setiap personel SATKER ITWASDA POLDA Lampung dalam membentuk insan Polri yang Profesional, Modern, dan Terpercaya yang nantinya akan menjadi kebanggaan masyarakat sehingga Polri dapat memaksimalkan personelnya guna keprofesionalan (profesionalisme) setiap petugas/ anggota penyelenggara pelayanan publik.

Oleh sebab itu, setiap anggota Polisi sebagai pelayan masyarakat harus akuntabilitas, responsif, efisien, serta berorientasi pada pelayanan profesional dan taat asas. Sejatinya tidak ada alasan bagi setiap insan Polisi untuk tidak profesional, sebab setiap warga negara yang telah menjadi Polisi telah mengikuti pendidikan pembentukan (Diktuk) Polri baik tingkat Tamtama, Bintara, mau pun Perwira. Hal ini, berarti setiap insan Polri telah melalui seleksi yang ketat setelah mengikuti pendidikan kepolisian (knowledge and skill). Hal ini sesuai dengan yang ditetapkan dalam Undang-Undang Republik Indonesia Nomor 25 Tahun 2009 Tentang 'Pelayanan Publik'.

\section{KESIMPULAN}

Berdasarkan hasil dan pembahasan yang telah diuraikan adalah sebagai berikut:

$>$ Faktor penyebab kurang optimalnya kemampuan yang dimiliki personel SATKER ITWASDA POLDA Lampung dalam menganalisis sarana dan prasarana bidang keuangan untuk meningkatkan kualitas pelayanan SATKER, sehingga berimplikasi pada kuantitas karena institusi Polri harus mampu melaksanakan tugas pokok dan fungsinya dengan baik sesuai ekspektasi masyarakat yang selalu berubah mengikuti perkembangan lingkungan sosial kemasyarakatan yang bergerak sangat cepat. Hal inilah yang menjadi hambatan personel SATKER ITWASDA POLDA Lampung dalam membentuk insan Polri yang Profesional, Modern, dan Terpercaya, menjadi kebanggaan masyarakat, karena dapat memaksimalkan personelnya guna keprofesionalan (profesionalisme) setiap petugas / anggota penyelenggara pelayanan publik (dalam hal ini Polri).

Kemampuan yang digunakan oleh personel SATKER ITWASDA POLDA Lampung saat ini dinilai kurang efektif. Hal ini terbukti dengan adanya pelayanan dari personel SATKER yang masih belum terselesaikan. Diperlukan pengetahuan dan kemampuan dalam menggunakan metode yang lebih efektif dan efisien agar pelayanan dalam bidang sarana dan prasana keuangan lebih ditingkatkan.

\section{DAFTAR PUSTAKA}

Fikri, S., Wiyani, W., \& Suwandaru, A. (2016). Pengaruh Kualitas Pelayanan Terhadap Kepuasan Dan Loyalitas Mahasiswa. Jurnal Bisnis Dan Manajemen, 3, 15.

Hasibuan, S. P. M. (2005). Manajemen Sumber Daya Manusia. Edisi Revisi. Bumi Aksara. 
Megasari, R. (2014). Peningkatan Pengelolaan Sarana Dan Prasarana Pendidikan Untuk Meningkatan Kualitas Pembelajaran Di Smpn 5 Bukittinggi.

Jurnal Administrasi Pendidikan, 2 No. 1, 13.

Ristiani, I. Y. (2017). Pengaruh Sarana Prasarana Dan Kualitas Pelayanan Terhadap Kepuasan Pasien. 12.

Rodin, R. (2019). Penerapan Fungsi Manajemen Dalam Pengelolaan Perpustakaan Madrasah Aliyah (Studi Kasus Di Perpustakaan Man 2 Palembang). Tik Ilmeu : Jurnal Ilmu Perpustakaan Dan Informasi, 3(2), 125.

Https://Doi.Org/10.29240/Tik.V3i2. 1005

Ulandari, S., \& Yudawati, S. (2019). Analisis Kualitas Pelayanan, Sarana Prasarana Dan Lingkungan Terhadap Kepuasan Pasien. Care: Jurnal Ilmiah Ilmu Kesehatan, 7(2), 39.

Https://Doi.Org/10.33366/Jc.V7i2.1 087

Yuliati, A. L. (2016). Pengaruh Kualitas Pelayanan Terhadap Kepuasan Pelanggan Pada Jne Cabang Bandung Januar Efendi Panjaitan. Derema Jurnal Manajemen, 11 No. 2(2), 25. 